\title{
Association of four GSTs gene polymorphisms with Parkinson disease: A meta-analysis
}

\author{
Dongjun Dai ${ }^{1,2^{*}}$, Yunliang Wang ${ }^{3 * \#}$, Lingyan Wang ${ }^{4 *}$, Jinfeng $\mathrm{Li}^{3}$, Hanlin Zhou ${ }^{1}$, Qingqing Ma ${ }^{1}$, \\ Xingyu Zhou', Jun Pan ${ }^{1}$, Guanghui Pan ${ }^{1}$, Cheng Chen ${ }^{1}$, Limin Xu ${ }^{1}$, Ping Ru ${ }^{1}$, Hui Wang ${ }^{1}$, \\ Shengqian Zhu' ${ }^{1}$, Yuelong $\mathrm{Lv}^{1}$, Leiting $\mathrm{Xu}^{1}$, Meng Ye ${ }^{2 \#}$, Shiwei Duan ${ }^{1 \#}$ \\ ${ }^{1}$ Zhejiang Provincial Key Laboratory of Pathophysiology, School of Medicine, Ningbo University, Ningbo, China \\ ${ }^{2}$ The Affiliated Hospital, Ningbo University, Ningbo, China \\ ${ }^{3}$ Department of neurology, the 148 Central Hospital of PLA, Zibo, China \\ ${ }^{4}$ Bank of Blood Products, Ningbo No.2 Hospital, Ningbo, China \\ Email: " wangyunliang81@163.com, " yemeng@nbu.edu.cn, ${ }^{\#}$ duanshiwei@nbu.edu.cn
}

Received 2 November 2013; revised 17 December 2013; accepted 4 January 2014

Copyright (C) 2014 Dongjun Dai et al. This is an open access article distributed under the Creative Commons Attribution License, which permits unrestricted use, distribution, and reproduction in any medium, provided the original work is properly cited. In accordance of the Creative Commons Attribution License all Copyrights @ 2014 are reserved for SCIRP and the owner of the intellectual property Dongjun Dai et al. All Copyright (C 2014 are guarded by law and by SCIRP as a guardian.

\section{ABSTRACT}

Parkinson disease (PD) is a neurological disorder with huge destruction to human body, which affects approximately $2 \%$ of the population aged 65 years or older. As antioxidants in the stress defence systems, glutathione S-transferases (GSTs) are dimeric cytosolic enzymes with an important role in the pathogenesis of PD. The aim of this study was to evaluate the association between the polymorphisms of GST genes and PD. Meta-analyses were conducted from 17 studies (38 stages) among 3419 cases and 5686 controls between four polymorphisms (GSTT1 deletion polymorphism; GSTM1 deletion polymorphism; GSTP1104: rs1695; GSTP1-114: rs1799811) and PD. There is no significant association between the four GST gene variants and PD. A further subgroup study by ethnicity observed a risky role of GSTM1 deletion polymorphism with PD in Europeans $(p=0.013$, OR = $1.126,95 \% \mathrm{CI}=1.025-1.236$ ), and a protective role of GSTM1 deletion polymorphism with PD in Latin Americans $(p=0.032$, OR $=0.750,95 \% \mathrm{CI}=0.577$ 0.975). Our meta-analysis suggested that GSTM1 deletion polymorphism increased the risk of PD in Europeans, but reduced the risk of PD in Latin Americans. Future large-scale studies might be needed to confirm the ethnic difference of GSTM1 deletion polymorphism, and to check whether there was significant association of PD for other GST genetic polymorphisms.

${ }^{*} \mathrm{DD}, \mathrm{YW}$ and LW are co-first authors of this work.

\#Corresponding authors.

\section{KEYWORDS}

Parkinson; GSTM1 Deletion Polymorphism; Meta-Analysis; Europeans; GSTT1; GSTP1

\section{INTRODUCTION}

Parkinson disease (PD, OMIM 168600) is a neurological disorder that affects approximately $2 \%$ of the population aged 65 years or older [1]. The clinical features of PD are resting tremor, muscular rigidity, bradykinesia, and postural instability [2]. PD can cause a huge destruction to human body, including pain [3], depression [4,5], visual hallucinations [6], dementia [7] and other non-motor symptoms [8-11].

PD is a complex disease that may be contributed by environmental and genetic factors. Environmental hypothesis was dominant for much of the 20th century [2]. PD was shown to be associated with environmental factors such as encephalitis [12], oxidative stress [13], smoking and coffee [14], and environmental toxins [15]. Although recent genetic studies have discovered a handful of genetic markers of PD [16-18], the aetiology of PD remains unknown.

Glutathione S-transferases (GST) conjugate glutathione to electrophilic species that can adduct protein or DNA [19]. GST enzymes can detoxify many oxidative products and thus lower the PD risk in the smokers [20] and the people with pesticides exposure [21]. GST genes that have been studied most in the PD association include GSTT1 [22-33] on chromosome 22q11.23, GSTM1 [2228,30,32-38] on chromosome 1p13.3, and GSTP1 [23,26, 
28-31,33,37,38] on chromosome 11q13. The phenotypic absence of GSTM1 and GSTT1 activity is the consequences of homozygous deletion of these genes [39, 40]. The GSTP1-104 and GSTP1-114 were A to G and C to T transitions that may have an impact on gene function [23].

Previous case-control studies showed inconsistent results between GST genes and PD (Table 1). Discrepancy among previous studies might be due to different ethnic background, or inefficient sample size [41], or the uncorrected physiological status among different studies [42]. Meta-analysis is a wildly used method to augment statistical power and to draw a more convincing conclusion through the pooling of data from individual association study [43]. The goal of our meta-analyses was to find out the causes of the inconsistent results among various case-control association studies, and to evaluate the contribution of GST variants to PD.

\section{MATERIALS AND METHODS}

\subsection{Data Collection}

We performed a systematic literature searching in online databases (PubMed Wan Fang, Wei Pu and CNKI) without time and language restriction, using the following keywords "Parkinson GSTT1 association or Parkinson GSTT1 polymorphism”, "Parkinson GSTM1 association or Parkinson GSTM1 polymorphism”, "Parkinson GSTP1 association or Parkinson GSTP1 polymorphism” to identify available articles. The inclusion criteria of the literatures for the meta-analyses comprise the following items: (1) It was an original case-control study with an assessment of the association between GSTT1, GSTM1, GSTP1 and PD in humans; (2) It contains sufficient information to infer the odd ratios (ORs) and 95\% confi- dential intervals (95\% CIs); (3) Genotype distribution of each polymorphism in controls met Hardy-Weinberg equilibrium (HWE). All of the case-control studies about GSTs and PD were fully considered and carefully selected in August 2013. The following information was extracted or calculated from each study: Genetic locus, first author's name, year of publication, country, ethnicity, numbers of cases and controls, control source, HWE for controls, if the study had significant association with PD and power analysis for each study involved in the meta-analyses.

\subsection{Statistical Analysis}

Arlequin program was used to test HWE [44]. Statistical heterogeneity across studies included in the meta-analysis was assessed by Cochran's Q statistic and $\mathrm{I}^{2}$ test [45] to decide the type of analysis. For the studies with minimal to moderate heterogeneity $\left(\mathrm{I}^{2}<50 \%\right)$, the fixedeffect model would be used for the meta-analysis. For the studies with significant heterogeneity $\left(\mathrm{I}^{2}>=50 \%\right)$, the random-effect model would be used. Funnel plots were also drawn to observe the potential publication bias. Statistical analysis of meta-analysis was carried out in Review Manager 5 and STATA statistical software $[46,47]$. Power and Sample Size Calculation program was applied to calculate the power of each study [48].

\section{RESULT}

As is shown in Figure 1, 21 potentially relevant articles were selected after removing duplicates. Among them, 17 studies [22-38] that met the inclusion criteria were involved in our meta-analyses. Among the involved studies, 3 studies for GSTP1-104 variant [26,29,31] were excluded for the deviation from HWE in controls $(p<$

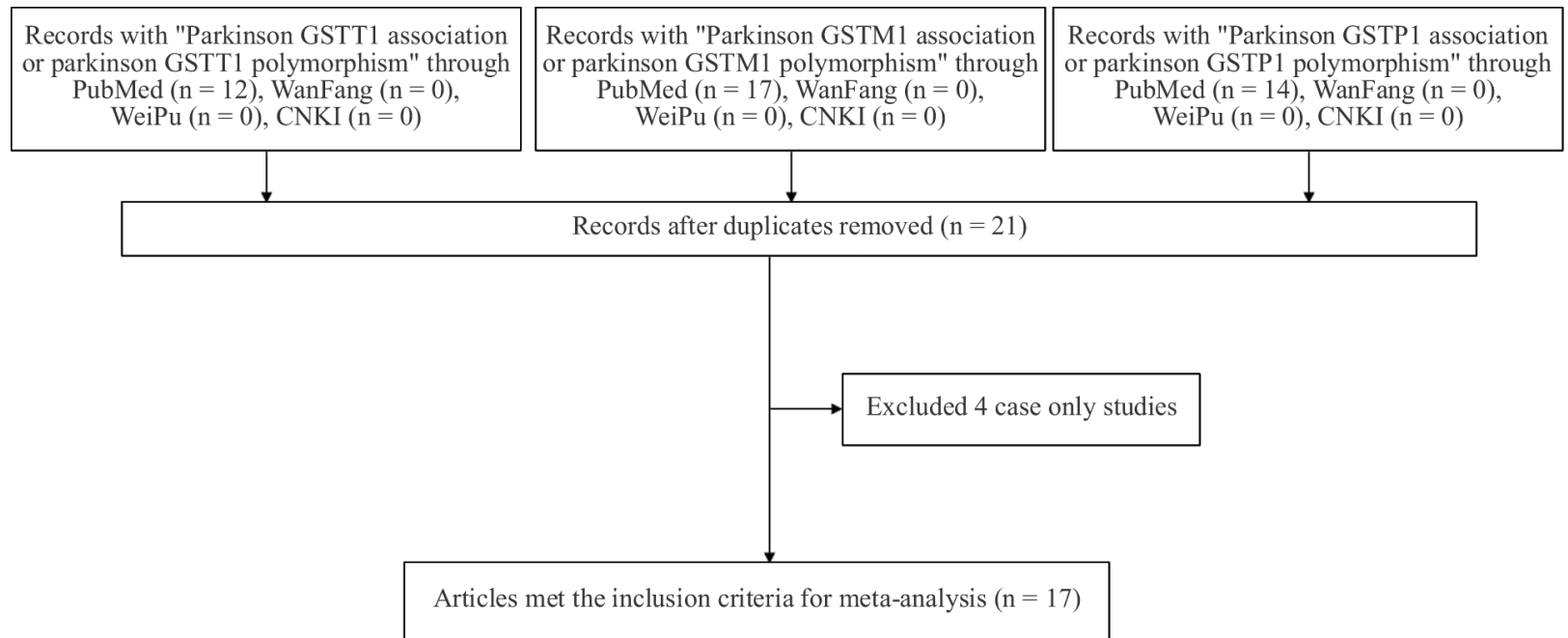

Figure 1. Flowchart of selection process in the meta-analyses. 
Table 1. Characteristics of the case-control studies in the current meta-analyses.

\begin{tabular}{|c|c|c|c|c|c|c|c|c|}
\hline First author & Year & Country & Ethnicity & Cases/controls & Control source & HWE & Result $^{*}$ & Power \\
\hline \multicolumn{9}{|l|}{ GSTT1 deletion } \\
\hline Alessandra Menegon & 1998 & Australia & Europeans & 95/95 & Hospital & NA & NS & 0.123 \\
\hline Maudy CMJ Stroombergen & 1999 & UK & Europeans & $167 / 225$ & Hospital & NA & S & 0.216 \\
\hline A. Rahbar & 2000 & Germany & Europeans & $149 / 99$ & Population & NA & NS & 0.137 \\
\hline A. Ahmadi & 2000 & Sweden & Europeans & $35 / 283$ & Hospital & NA & NS & 0.095 \\
\hline Samir N. Kelada & 2003 & USA & Europeans & $214 / 327$ & Hospital & NA & NS & 0.231 \\
\hline Angelika D. Wahner & 2007 & America & Europeans & $235 / 220$ & Population & NA & NS & 0.234 \\
\hline F D Dick & 2007 & UK & Europeans & $200 / 400$ & Population & NA & NS & NA \\
\hline Madhu Singh & 2008 & India & Asians & $70 / 100$ & Population & NA & NS & 0.094 \\
\hline C. Kiyohara & 2010 & Japan & Asians & 237/369 & Hospital & NA & NS & 0.340 \\
\hline Arindam Biswas & 2012 & India & Asians & $331 / 177$ & Hospital & NA & NS & 0.184 \\
\hline Samuel M. Goldman & 2012 & USA & Europeans & $87 / 343$ & Population & NA & NS & NA \\
\hline Tommaso Cornetta & 2013 & Italy & Europeans & $125 / 112$ & Hospital & NA & NS & 0.124 \\
\hline \multicolumn{9}{|l|}{ GSTM1 deletion } \\
\hline Alessandra Menegon & 1998 & Australia & Europeans & 95/95 & Population & NA & NS & 0.143 \\
\hline Nicholl & 1999 & UK & Europeans & $205 / 206$ & Hospital & NA & NS & 0.257 \\
\hline Maudy CMJ Stroombergen & 1999 & UK & Europeans & $166 / 225$ & Hospital & NA & S & 0.241 \\
\hline A. Rahbar & 2000 & Germany & Europeans & $149 / 99$ & Hospital & NA & NS & 0.168 \\
\hline A. Ahmadi & 2000 & Sweden & Europeans & $35 / 283$ & Hospital & NA & NS & 0.107 \\
\hline Shoji Harada & 2001 & Japan & Asians & $81 / 100$ & Hospital & NA & NS & 0.137 \\
\hline Samir N. Kelada & 2003 & USA & Europeans & $214 / 327$ & Hospital & NA & NS & 0.310 \\
\hline Angelika D. Wahner & 2007 & America & Europeans & $235 / 220$ & Population & NA & NS & 0.279 \\
\hline F D Dick & 2007 & UK & Europeans & $200 / 400$ & Population & NA & NS & NA \\
\hline Carolina Perez-Pastene & 2007 & Chile & L.A & $349 / 611$ & Population & NA & S & 0.458 \\
\hline R. Vilara & 2007 & Portugal & Europeans & 94/95 & Population & NA & NS & 0.142 \\
\hline C. Kiyohara & 2010 & Japan & Asians & 237/369 & Hospital & NA & NS & 0.335 \\
\hline Giuseppe De Palma & 2010 & Italy & Europeans & $742 / 1923$ & Population & NA & NS & 0.845 \\
\hline Arindam Biswas & 2012 & India & Asians & $331 / 177$ & Hospital & NA & NS & 0.251 \\
\hline Samuel M. Goldman & 2012 & UK & Europeans & $87 / 343$ & Population & NA & S & NA \\
\hline Tommaso Cornetta & 2013 & Italy & Europeans & $125 / 112$ & Hospital & NA & NS & 0.160 \\
\hline \multicolumn{9}{|l|}{ GSTP1-104 } \\
\hline Alessandra Menegon & 1998 & $\operatorname{Mix} * a$ & Europeans & 96/95 & Hospital & NA & S & 0.071 \\
\hline Samir N. Kelada & 2003 & America & Europeans & 213/329 & GHC & NO & S & NA \\
\hline Angelika D. Wahner & 2007 & America & Europeans & $235 / 220$ & Population & YES & NS & 0.254 \\
\hline R. Vilar & 2007 & Portuguese & Europeans & $96 / 96$ & Population & NA & S & 0.109 \\
\hline Madhu Singh & 2008 & India & Asians & $70 / 100$ & Population & NO & NS & NA \\
\hline
\end{tabular}


Continued

\begin{tabular}{|c|c|c|c|c|c|c|c|c|}
\hline C. Kiyohara & 2010 & Japan & Asians & $238 / 370$ & Hospital & YES & NS & 0.223 \\
\hline Giuseppe De Palma & 2010 & Mix*b & Europeans & 409/1016 & Population & NA & NS & 0.210 \\
\hline Arindam Biswas & 2012 & India & Africans & $331 / 177$ & Hospital & NO & NS & NA \\
\hline Tommaso Cornetta & 2013 & Italy & Europeans & $125 / 112$ & Hospital & NA & $\mathrm{S}$ & NA \\
\hline \multicolumn{9}{|l|}{ GSTP1-114 } \\
\hline Alessandra Menegon & 1998 & $\operatorname{Mix}^{*} \mathrm{a}$ & Europeans & 96/95 & Hospital & NA & S & 0.137 \\
\hline Samir N. Kelada & 2003 & America & Europeans & $214 / 330$ & GHC & YES & $\mathrm{S}$ & NA \\
\hline Angelika D. Wahner & 2007 & America & Europeans & $235 / 220$ & Population & YES & NS & 0.164 \\
\hline Giuseppe De Palma & 2010 & $\operatorname{Mix}^{*} b$ & Europeans & 409/1016 & Population & NA & NS & 0.123 \\
\hline
\end{tabular}

Mix ${ }^{*} a$, Queensland, Australia, America; Mix ${ }^{*} b$, Italy, Malta, Romania, Scotland, Sweden; GHC, Group Health Cooperative; HWE, Hardy-Weinberg equilibrium; L.A, Latin Americans; NA, Not applicable; Result”, The association between GST genes and PD; NS, No significant; S, Significant.

0.05). We were unable to test HWE for GSTT1 and GSTM1 deletions because there was no genotype information in the original reports. At last, we included 17 studies (38 stages) among 3419 cases and 5686 controls in the current meta-analyses of four GST gene variants (Table 1).

We observed no significant association between the four GST genes variants and PD (Table 2, Figure 2). A further subgroup study by ethnicity observed a risky role of GSTM1 deletion polymorphism with PD in Europeans ( $p=0.013$, OR $=1.126,95 \% \mathrm{CI}=1.025-1.236$, Figure 2 and Table 2), and a protective role of GSTM1 deletion polymorphism with PD in Latin Americans ( $p=0.032$, $\mathrm{OR}=0.750,95 \% \mathrm{CI}=0.577-0.975$, Figure 2 and Table 2). Statistically significant heterogeneity was found for the meta-analysis of GSTP1-104 ( $\mathrm{I}^{2}=79 \%$, Table 2$)$. No publication bias was observed for the meta-analyses of the four GST variants (Figure 3).

\section{DISCUSSION}

Our meta-analyses showed that GSTM1 deletion polymorphism was a risky and protective factor in PD for Europeans and Latin Americans, respectively (Table 2 and Figure 2). GSTM1 encodes a key GST that plays an important role against oxidative stress [49], and thus defenses PD. GSTM1 deletion polymorphism showed a wide association with diseases such as coronary heart disease [50], thyroid carcinoma [51], myelodysplastic syndrome [52], oral cancer [53] and PD [22,32,34]. Homozygous deletion genotypes of GSTM1 and GSTT1 were relatively common in Caucasian populations [54], and disease prevalence by WHO showed that Europe was the most severe region of PD in the world. We performed a further subgroup study by ethnicity that showed a significant association between GSTM1 deletion polymorphism and $\mathrm{PD}$ in Europeans $(p=0.013, \mathrm{OR}=1.126,95 \% \mathrm{CI}=$
1.025 - 1.236, $\mathrm{I}^{2}=0 \%$, Table 2). On the contrary, there was a significant protective role of GSTM1 deletion polymorphism for PD in Latin American population ( $\mathrm{p}=$ 0.032 , OR $=0.750,95 \%$ CI $=0.577-0.975$, Table 2). Since the latter result was produced by only one study [34] with relative low power (power $=0.458$ ), future study was needed to confirm this ethnic difference of GSTM1 deletion polymorphism in the risk of PD.

Although we didn't observe a significant association between GSTP1-104 and PD in the combined samples, subgroup meta-analyses by ethnicity indicated a trend of significance in Europeans ( $p=0.104$, Table 2) and Asians ( $p=0.096$, Table 2). GSTP1-104-A allele frequency showed a significant ethnic difference between Asians (Hapmap-JPT: 0.907) and Europeans (HapmapCEU: 0.593, Fst $=0.16$ ). As is shown in Table 2, the power is 0.476 in Europeans and 0.223 in Asians, indicating that larger sample size is needed to validate the association of GSTP1-104 and PD in the future.

To be noted, a former meta-analysis with 4 studies in GSTT1 and GSTM1, and 1 study in GSTP1 in 2000 [55] showed a significant association between GSTT1 and PD, and no significant results were found in GSTM1 and GSTP1. Compared with the former meta-analysis, our study included 8, 12 and 8 more studies in GSTT1, GSTM1 and GSTP1, respectively. We also performed an ethnic subgroup study that previous study did not perform. We performed HWE test for the controls in GSTP1 and excluded 3 case-control studies that failed to meet HWE in the control samples [26,29,31]. With an enhanced power, more comprehensive analysis and stricter selection criteria, our meta-analyses produced a more reliable conclusion than the previous meta-analysis studies.

Several limitations in our study needed to be carefully considered. Firstly, the number of associations in nonCaucasian populations was limited. This suggested that 


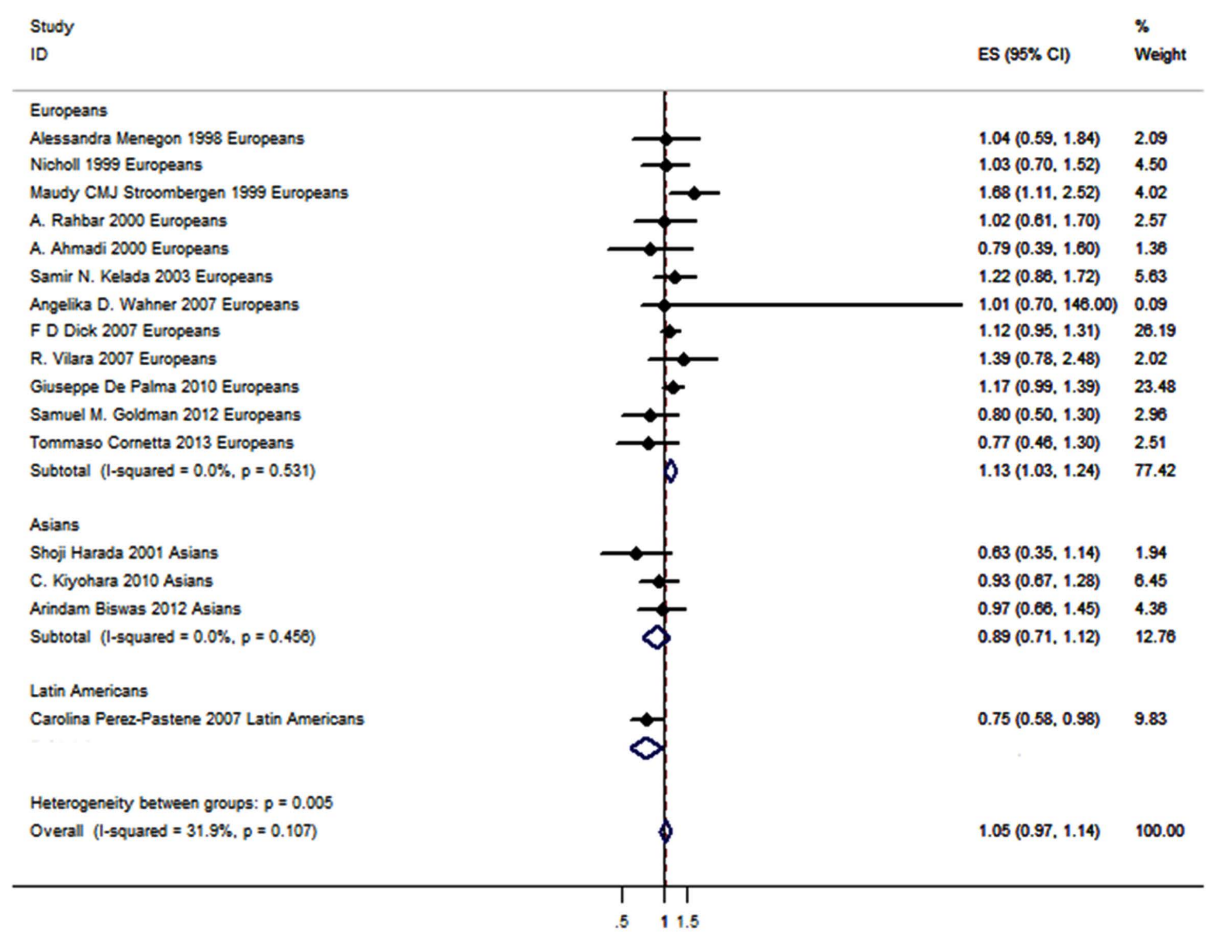

Figure 2. Forest plot of GSTM1 deletion polymorphism with PD.

Table 2. Meta-analyses of the GSTT1 deletion polymorphism, GSTM1 deletion polymorphism, GSTP1-104 and GSTP1-114 with PD.

\begin{tabular}{|c|c|c|c|c|c|c|c|}
\hline Genetic model & Ethnicity & Stages $^{*}$ & Cases/Controls & OR (95\% CI) & $P$ value & $\mathrm{I}^{2}$ & Power \\
\hline \multicolumn{8}{|l|}{ GSTT1 deletion } \\
\hline \multirow[t]{3}{*}{ Overall (Null vs Present) } & Overall & 12 & $1945 / 2750$ & $1.042(0.933-1.164)$ & 0.467 & $39.10 \%$ & NA \\
\hline & Europeans & 9 & $1307 / 2104$ & $1.099(0.972-1.242)$ & 0.132 & $35.00 \%$ & NA \\
\hline & Asians & 3 & $638 / 646$ & $0.820(0.632-1.064)$ & 0.135 & $0.00 \%$ & NA \\
\hline \multicolumn{8}{|l|}{ GSTM1 deletion } \\
\hline \multirow[t]{4}{*}{ Overall (Null vs Present) } & Overall & 16 & 3345/5585 & $1.050(0.967$ - 1.139) & 0.249 & $31.90 \%$ & NA \\
\hline & Europeans & 12 & $2347 / 4328$ & $1.126(1.025-1.236)$ & 0.013 & $0.00 \%$ & NA \\
\hline & Asians & 3 & $649 / 646$ & 0.889 (0.706 - 1.119) & 0.318 & $0.00 \%$ & NA \\
\hline & Latin Americans & 1 & $349 / 611$ & $0.750(0.577-0.975)$ & 0.032 & NA & NA \\
\hline \multicolumn{8}{|l|}{ GSTP1-104 } \\
\hline \multirow[t]{3}{*}{ Overall (A vs G) } & Overall & 5 & $994 / 1727$ & $1.140(0.630-2.070)$ & 0.66 & $92.00 \%$ & 0.679 \\
\hline & Europeans & 4 & $756 / 1357$ & $1.435(0.928-2.218)$ & 0.104 & $76.00 \%$ & 0.476 \\
\hline & Asians & 1 & $238 / 320$ & $0.760(0.550-1.050)$ & 0.096 & NA & 0.223 \\
\hline Dominant (AA/AG vs GG) & Overall & 3 & $598 / 702$ & $1.110(0.890-1.400)$ & 0.36 & $33.00 \%$ & 0.629 \\
\hline Recessive (GG vs AG/GG) & Overall & 2 & $473 / 590$ & $0.960(0.740-1.240)$ & 0.77 & $36.00 \%$ & 0.52 \\
\hline Additive (AA vs GG) & Overall & 2 & 298/390 & $0.980(0.550-1.720)$ & 0.09 & $0.00 \%$ & 0.134 \\
\hline \multicolumn{8}{|l|}{ GSTP1-114 } \\
\hline Overall (C vs T) & Overall & 4 & $874 / 1591$ & $1.030(0.810-1.330)$ & 0.79 & $0.00 \%$ & 0.314 \\
\hline Dominant (CC/CT vs TT) & Overall & 2 & $448 / 549$ & $1.150(0.840-1.590)$ & 0.38 & $0.00 \%$ & 0.364 \\
\hline Recessive (CC vs CT/TT) & Overall & 2 & $448 / 549$ & $0.280(0.070-1.160)$ & 0.08 & $20.00 \%$ & 0.09 \\
\hline Additive (CC vs TT) & Overall & 2 & $360 / 459$ & $0.290(0.070-1.210)$ & 0.09 & $23.00 \%$ & 0.089 \\
\hline
\end{tabular}

Stages $^{*}$ : Amount of stages; NA, Not applicable. 

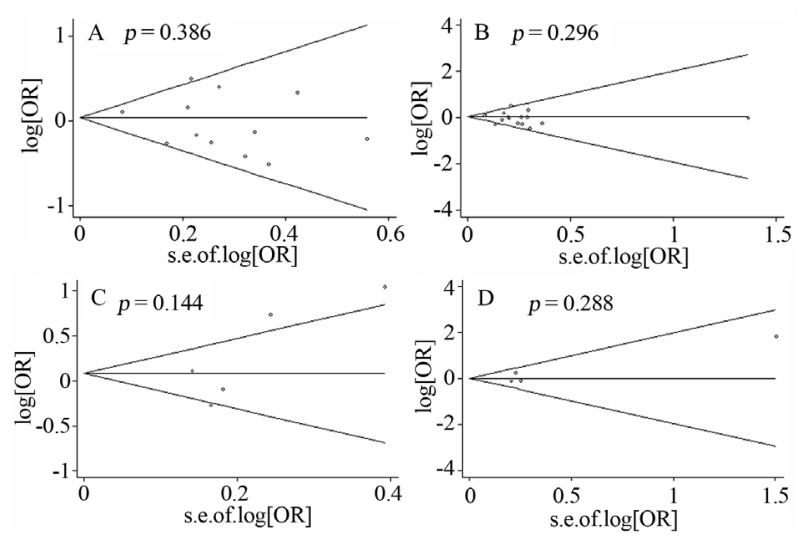

Figure 3. Funnel plots of four SNPs with PD. A) Funnel plot of GSTT1 deletion polymorphism with PD; B) Funnel plot of GSTM1 deletion polymorphism with PD; C) Funnel plot of GSTP1-104 polymorphism with PD; D) Funnel plot of GSTM1114 polymorphism with PD.

non-significant results in Asians needed to be taken with caution. Future studies with larger samples size are required to establish the association of GST gene polymorphisms with PD. Secondly, PD is a complex disease that different physiological status of PD may exist in the cases. All the existing case-control studies didn't perform a stratified analysis by the PD stage. This may partially explain the discrepancies in the current case-control studies. Thirdly, genetic heterogeneity may exist for the polymorphisms of GST genes. Our meta-analyses only focused on four polymorphisms that might not fully represent the overall contribution of GST gene polymorphisms. Other GST gene polymorphisms need to be analyzed for their contribution to $\mathrm{PD}$ in the future. Fourthly, all the $\mathrm{p}$ values are not corrected by the number of tests. The positive findings in the present study need to be validated in the future study in order to prevent the false positives caused by multiple testing in our analyses.

In conclusion, our meta-analysis observed a significant association of GSTM1 deletion polymorphism with PD in Europeans. Further large-scale studies are required to evaluate the polymorphisms of GSTs that might contribute to the risk of PD.

\section{ACKNOWLEDGEMENTS}

The research was supported by the grants from: National Natural Science Foundation of China (31100919), Natural Science Foundation of Zhejiang Province (LR13H020003), K. C. Wong Magna Fund in Ningbo University, and Ningbo social development research projects (2012C50032).

\section{REFERENCES}

[1] Elbaz, A., Bower, J.H., Maraganore, D.M., McDonnell, S.K., Peterson, B.J., Ahlskog, J.E., et al., (2002) Risk tables for parkinsonism and Parkinson's disease. Journal of Clinical Epidemiology, 55, 25-31. http://dx.doi.org/10.1016/S0895-4356(01)00425-5

[2] Dauer, W. and Przedborski, S. (2003) Parkinson's disease: Mechanisms and models. Neuron, 39, 889-909. http://dx.doi.org/10.1016/S0896-6273(03)00568-3

[3] Mylius, V., Engau, I., Teepker, M., Stiasny-Kolster, K., Schepelmann, K., Oertel, W.H., et al., (2009) Pain sensitivity and descending inhibition of pain in Parkinson's disease. Journal of Neurology, Neurosurgery \& Psychiatry, 80, 24-28.

http://dx.doi.org/10.1136/jnnp.2008.145995

[4] Grachev, I.D. (2013) Dopamine transporter imaging with [123I]FP-CIT (DaTSCAN) in Parkinson's disease with depressive symptoms: A biological marker for causal relationships? Journal of Neurology, Neurosurgery \& Psychiatry, 2013.

[5] Blonder, L.X., Slevin, J.T., Kryscio, R.J., Martin, C.A., Andersen, A.H., Smith, C.D., et al. (2013) Dopaminergic modulation of memory and affective processing in Parkinson depression. Psychiatry Research, 2013.

[6] Lee, J.Y., Kim, J.M., Ahn, J., Kim, H.J., Jeon, B.S. and Kim, T.W. (2013) Retinal nerve fiber layer thickness and visual hallucinations in Parkinson's Disease. Movement Disorders, 2013.

[7] Aarsland, D., Zaccai, J. and Brayne, C. (2005) A systematic review of prevalence studies of dementia in Parkinson's disease. Movement Disorder, 20, 1255-1263. http://dx.doi.org/10.1002/mds.20527

[8] Gan, E.C., Lau, D.P. and Cheah, K.L. (2010) Stridor in Parkinson's disease: A case of “dry drowning”? The Journal of Laryngology \& Otology, 124, 668-673. http://dx.doi.org/10.1017/S0022215109992222

[9] Klebe, S., Golmard, J.L., Nalls, M.A., Saad, M., Singleton, A.B., Bras, J.M., et al. (2013) The Val158Met COMT polymorphism is a modifier of the age at onset in Parkinson's disease with a sexual dimorphism. Journal of Neurology, Neurosurgery \& Psychiatry, 84, 666-673. http://dx.doi.org/10.1136/jnnp-2012-304475

[10] Rode, J., Bentley, A. and Parkinson, C. (1990) Paraganglial cells of urinary bladder and prostate: Potential diagnostic problem. Journal of Clinical Pathology, 43, 13-16. http://dx.doi.org/10.1136/jcp.43.1.13

[11] Najafi, M.R., Chitsaz, A., Askarian, Z. and Najafi, M.A. (2013) Quality of sleep in patients with Parkinson's disease. International Journal of Preventive Medicine, 4, S229-S233.

[12] Horvath, J., Burkhard, P.R., Bouras, C. and Kovari, E. (2013) Etiologies of Parkinsonism in a century-long autopsy-based cohort. Brain Pathology, 23, 28-33. http://dx.doi.org/10.1111/j.1750-3639.2012.00611.x

[13] Olanow, C.W. and Tatton, W.G. (1999) Etiology and pathogenesis of Parkinson's disease. Annual Review of Neuroscience, 22, 123-144.

http://dx.doi.org/10.1146/annurev.neuro.22.1.123

[14] Wirdefeldt, K., Adami, H.O., Cole, P., Trichopoulos, D. and Mandel, J. (2011) Epidemiology and etiology of Parkinson's disease: A review of the evidence. European 
Journal of Epidemiology, 26, S1-S58. http://dx.doi.org/10.1007/s10654-011-9581-6

[15] Vaglini, F., Viaggi, C., Piro, V., Pardini, C., Gerace, C., Scarselli, M., et al. (2013) Acetaldehyde and parkinsonism: Role of CYP450 2E1. Frontiers in Behavioral Neuroscience, 7,71 .

http://dx.doi.org/10.3389/fnbeh.2013.00071

[16] Lill, C.M., Roehr, J.T., McQueen, M.B., Kavvoura, F.K., Bagade, S., Schjeide, B.M., et al. (2012) Comprehensive research synopsis and systematic meta-analyses in Parkinson's disease genetics: The PDGene database. PLoS Genet, 8, e1002548. http://dx.doi.org/10.1371/journal.pgen.1002548

[17] McInerney-Leo, A., Hadley, D.W., Gwinn-Hardy, K. and Hardy, J. (2005) Genetic testing in Parkinson's disease. Movement Disorders, 20, 1-10. http://dx.doi.org/10.1002/mds.20316

[18] Bekris, L.M., Mata, I.F. and Zabetian, C.P. (2010) The genetics of Parkinson disease. Journal of Geriatric Psychiatry and Neurology, 23, 228-242. http://dx.doi.org/10.1177/0891988710383572

[19] Travers, M.E., Mackay, D.J., Dekker Nitert, M., Morris, A.P., Lindgren, C.M., Berry, A., et al. (2013) Insights into the molecular mechanism for type 2 diabetes susceptibility at the KCNQ1 locus from temporal changes in imprinting status in human islets. Diabetes, 62, 987-992. http://dx.doi.org/10.2337/db12-0819

[20] Ritz, B., Ascherio, A., Checkoway, H., Marder, K.S., Nelson, L.M., Rocca, W.A., et al. (2007) Pooled analysis of tobacco use and risk of Parkinson disease. Archives of Neurology, 64, 990-997. http://dx.doi.org/10.1001/archneur.64.7.990

[21] Priyadarshi, A., Khuder, S.A., Schaub, E.A. and Shrivastava, S. (2000) A meta-analysis of Parkinson's disease and exposure to pesticides. Neurotoxicology, 21, 435440.

[22] Stroombergen, M.C. and Waring, R.H. (1999) Determination of glutathione S-transferase mu and theta polymorphisms in neurological disease. Human \& Experimental Toxicology, 18, 141-145. http://dx.doi.org/10.1191/096032799678839815

[23] Menegon, A., Board, P.G., Blackburn, A.C., Mellick, G.D. and Le Couteur, D.G. (1998) Parkinson's disease, pesticides, and glutathione transferase polymorphisms. Lancet, 352, 1344-1346. http://dx.doi.org/10.1016/S0140-6736(98)03453-9

[24] Rahbar, A., Kempkes, M., Muller, T., Reich, S., Welter, F.L., Meves, S., et al. (2000) Glutathione S-transferase polymorphism in Parkinson's disease. Journal of Neural Transmission, 107, 331-334. http://dx.doi.org/10.1007/s007020050027

[25] Ahmadi, A., Fredrikson, M., Jerregard, H., Akerback, A., Fall, P.A., Rannug, A., et al. (2000) GSTM1 and mEPHX polymorphisms in Parkinson's disease and age of onset. Biochemical and Biophysical Research Communications, 269, 676-680. http://dx.doi.org/10.1006/bbrc.2000.2338

[26] Kelada, S.N., Stapleton, P.L., Farin, F.M., Bammler, T.K., Eaton, D.L., Smith-Weller, T., et al. (2003) Glutathione
S-transferase M1, T1, and P1 polymorphisms and Parkinson's disease. Neuroscience Letters, 337, 5-8. http://dx.doi.org/10.1016/S0304-3940(02)01286-7

[27] Dick, F.D., De Palma, G., Ahmadi, A., Osborne, A., Scott, N.W., Prescott, G.J., et al. (2007) Gene-environment interactions in parkinsonism and Parkinson's disease: The Geoparkinson study. Occupational and Environmental Medicine, 64, 673-680. http://dx.doi.org/10.1136/oem.2006.032078

[28] Wahner, A.D., Glatt, C.E., Bronstein, J.M. and Ritz, B. (2007) Glutathione S-transferase mu, omega, pi, and theta class variants and smoking in Parkinson's disease. $\mathrm{Neu}$ roscience Letters, 413, 274-278.

http://dx.doi.org/10.1016/j.neulet.2006.11.053

[29] Singh, M., Khan, A.J., Shah, P.P., Shukla, R., Khanna, V.K. and Parmar, D. (2008) Polymorphism in environment responsive genes and association with Parkinson disease. Molecular and Cellular Biochemistry, 312, 131138. http://dx.doi.org/10.1007/s11010-008-9728-2

[30] Kiyohara, C., Miyake, Y., Koyanagi, M., Fujimoto, T., Shirasawa, S., Tanaka, K., et al. (2010) GST polymorphisms, interaction with smoking and pesticide use, and risk for Parkinson's disease in a Japanese population. Parkinsonism \& Related Disorders, 16, 447-452. http://dx.doi.org/10.1016/j.parkreldis.2010.04.009

[31] Biswas, A., Sadhukhan, T., Bose, K., Ghosh, P., Giri, A.K., Das, S.K., et al. (2012) Role of glutathione Stransferase T1, M1 and P1 polymorphisms in Indian Parkinson's disease patients. Parkinsonism \& Related Disorders, 18, 664-665. http://dx.doi.org/10.1016/j.parkreldis.2011.09.019

[32] Goldman, S.M., Kamel, F., Ross, G.W., Bhudhikanok, G.S., Hoppin, J.A., Korell, M., et al. (2012) Genetic modification of the association of paraquat and Parkinson's disease. Movement Disorders, 27, 1652-1658. http://dx.doi.org/10.1002/mds.25216

[33] Cornetta, T., Patrono, C., Terrenato, I., De Nigris, F., Bentivoglio, A.R., Testa, A., et al. (2013) Epidemiological, clinical, and molecular study of a cohort of Italian Parkinson disease patients: association with glutathioneS-transferase and DNA repair gene polymorphisms. Cellular and Molecular Neurobiology, 33, 673-680. http://dx.doi.org/10.1007/s10571-013-9933-8

[34] Perez-Pastene, C., Graumann, R., Diaz-Grez, F., Miranda, M., Venegas, P., Godoy, O.T., et al. (2007) Association of GST M1 null polymorphism with Parkinson's disease in a Chilean population with a strong Amerindian genetic component. Neuroscience Letters, 418, 181-185. http://dx.doi.org/10.1016/j.neulet.2007.03.024

[35] Nicholl, D.J., Bennett, P., Hiller, L., Bonifati, V., Vanacore, N., Fabbrini, G., et al. (1999) A study of five candidate genes in Parkinson's disease and related neurodegenerative disorders. European Study Group on Atypical Parkinsonism. Neurology, 53, 1415-1421. http://dx.doi.org/10.1212/WNL.53.7.1415

[36] Harada, S., Fujii, C., Hayashi, A. and Ohkoshi, N. (2001) An association between idiopathic Parkinson's disease and polymorphisms of phase II detoxification enzymes: Glutathione $S$-transferase M1 and quinone oxidoreductase 
1 and 2. Biochemical and Biophysical Research Communications, 288, 887-892.

http://dx.doi.org/10.1006/bbrc.2001.5868

[37] Vilar, R., Coelho, H., Rodrigues, E., Gama, M.J., Rivera, I., Taioli, E. and Lechner, M.C. (2007) Association of A313 $\mathrm{G}$ polymorphism $\left(G S T P 1^{*} B\right)$ in the glutathione-Stransferase $P 1$ gene with sporadic Parkinson's disease. European Journal of Neurology, 14, 156-161. http://dx.doi.org/10.1111/j.1468-1331.2006.01590.x

[38] De Palma, G., Dick, F.D., Calzetti, S., Scott, N.W., Prescott, G.J., Osborne, A., Haites, N., Mozzoni, P., Negrotti, A., Scaglioni, A. and Mutti, A. (2010) A case-control study of Parkinson's disease and tobacco use: Gene-tobacco interactions. Movement Disorders, 25, 912-919. http://dx.doi.org/10.1002/mds.22980

[39] Pemble, S., Schroeder, K.R., Spencer, S.R., Meyer, D.J., Hallier, E., Bolt, H.M., Ketterer, B. and Taylor, J.B. (1994) Human glutathione S-transferase theta (GSTT1): cDNA cloning and the characterization of a genetic polymorphism. Biochemical Journal, 300, 271-276.

[40] Seidegard, J. and Pero, R.W. (1988) The genetic variation and the expression of human glutathione transferase mu. Klinische Wochenschrift, 66, 125-126.

[41] Button, K.S., Ioannidis, J.P., Mokrysz, C., Nosek, B.A., Flint, J., Robinson, E.S. and Munafò, M.R. (2013) Power failure: Why small sample size undermines the reliability of neuroscience. Nature Reviews Neuroscience, 14, 365376. http://dx.doi.org/10.1038/nrn3475

[42] Xu, W.D., Zhou, M., Peng, H., Pan, H.F. and Ye, D.Q. (2013) Lack of association of IL-6 polymorphism with rheumatoid arthritis/type 1 diabetes: A meta-analysis. Joint Bone Spine, 80, 477-481.

[43] Tao, J.H., Zou, Y.F., Feng, X.L., Li, J., Wang, F., Pan, F.M. and Ye, D.Q. (2011) Meta-analysis of TYK2 gene polymorphisms association with susceptibility to autoimmune and inflammatory diseases. Molecular Biology Reports, 38, 4663-4672. http://dx.doi.org/10.1007/s11033-010-0601-5

[44] Excoffier, L., Laval, G. and Schneider, S. (2005) Arlequin (version 3.0): An integrated software package for population genetics data analysis. Evolutionary Bioinformatics Online, 1, 47-50.

[45] Coory, M.D. (2010) Comment on: Heterogeneity in metaanalysis should be expected and appropriately quantified. International Journal of Epidemiology, 39, 932. http://dx.doi.org/10.1093/ije/dyp157

[46] Kawalec, P., Mikrut, A., Wisniewska, N. and Pilc, A. (2013) The effectiveness of tofacitinib, a novel Janus kinase inhibitor, in the treatment of rheumatoid arthritis: A systematic review and meta-analysis. Clinical Rheuma- tology, 32, 1415-1424.

[47] Jamshidi Ardeshiri, M., Moosazadeh, M., Feizi Masouleh M., Kiani, A. and Fakhri, M. (2013) Prevalence of smoking in 15-64 years old population of north of iran: Meta-analysis of the results of non-communicable diseases risk factors surveillance system. Acta Medica Iranica, 51, 494-500.

[48] Gibson, E., Fenster, A. and Ward, A.D. (2013) The impact of registration accuracy on imaging validation study design: A novel statistical power calculation. Medical Image Analysis, 17, 805-815. http://dx.doi.org/10.1016/j.media.2013.04.008

[49] Han, J., Won, E.J., Hwang, D.S., Rhee, J.S., Kim, I.C. and Lee, J.S. (2013) Effect of copper exposure on GST activity and on the expression of four GSTs under oxidative stress condition in the monogonont rotifer, Brachionus koreanus. Comparative Biochemistry and Physiology Part C: Toxicology \& Pharmacology, 158, 91-100. http://dx.doi.org/10.1016/j.cbpc.2013.05.006

[50] Martin, N.J., Collier, A.C., Bowen, L.D., Pritsos, K.L., Goodrich, G.G., Arger, K., Cutterc, G. and Pritsosa, C.A. (2009) Polymorphisms in the NQO1, GSTT and GSTM genes are associated with coronary heart disease and biomarkers of oxidative stress. Mutation Research, 674, 93100. http://dx.doi.org/10.1016/j.mrgentox.2008.09.009

[51] Canbay, E., Dokmetas, S., Canbay, E.I., Sen, M. and Bardakci, F. (2003) Higher glutathione transferase GSTM1 0/0 genotype frequency in young thyroid carcinoma patients. Current Medical Research and Opinion, 19, 102-106. http://dx.doi.org/10.1185/030079902125001425

[52] Tsabouri, S.E., Georgiou, I., Alamanos, I. and Bourantas, K.L. (2000) Increased prevalence of GSTM(1) null genotype in patients with myelodysplastic syndrome: A casecontrol study. Acta Haematologica, 104, 169-173.

http://dx.doi.org/10.1159/000046510

[53] Park, L.Y., Muscat, J.E., Kaur, T., Schantz, S.P., Stern, J.C., Richie Jr., J.P. and Lazarus, P. (2000) Comparison of GSTM polymorphisms and risk for oral cancer between African-Americans and Caucasians. Pharmacogenetics, 10, 123-131. http://dx.doi.org/10.1097/00008571-200003000-00004

[54] Garte, S., Gaspari, L., Alexandrie, A.K., Ambrosone, C., Autrup, H., Autrup, J.L., et al., (2001) Metabolic gene polymorphism frequencies in control populations. Cancer Epidemiology, Biomarkers \& Prevention, 10, 1239-1248.

[55] Tan, E.K., Khajavi, M., Thornby, J.I., Nagamitsu, S., Jankovic, J. and Ashizawa, T. (2000) Variability and validity of polymorphism association studies in Parkinson's disease. Neurology, 55, 533-538. http://dx.doi.org/10.1212/WNL.55.4.533 